\title{
The Use of Artificial Intelligence in Personnel Management
}

\author{
Tappaskhanova E.O.* Mustafaeva Z.A. Tokmakova R. A.
}

\author{
Institute of Law, Economics and Finance, Kabardino-Balkarian State University, Russia \\ *Corresponding author. Email: tappazliza777@mail.ru
}

\begin{abstract}
The modern concept of enterprise management involves the separation from a large number of functional areas of managerial activity of the one that is associated with the management of the personnel component of production - the enterprise staff. Global technological and structural changes, increasing competition, the globalization of production, the development of international relations, cooperation and integration, make it increasingly difficult to manage this critical area of management. In these conditions, in many modern enterprises, human resources specialists have begun to actively use intelligent technologies to help recruiters in much shorter terms and more efficiently solve tasks such as recruitment and placement of personnel, staff training, its adaptation and assessment of work, etc. The main advantages and benefits, as well as the risks that artificial intelligence carries in the process of application in personnel management. The paper provides a comparative analysis of the use of artificial intelligence by foreign and Russian companies. The main achievements and problems in this area by domestic enterprises are identified. The study also led to the conclusion that there is a direct link between the use of artificial intelligence and the level of development of companies.
\end{abstract}

Keywords: personnel, HR-specialist, recruiter, competency model, job profile, artificial intelligence, chat bots

\section{INTRODUCTION}

As a result of the study, the task is to find out the causes of the problems that exist today in personnel management in the organization and justify the need for the use of artificial intelligence in this most important area of management.

The research topic is quite relevant to the modern time of development since personnel management experiences certain difficulties in connection with the globalization of technological and structural changes, increased competition, globalization of production, the development of international relations, cooperation and integration. In this regard, enterprises are looking for various innovative approaches to personnel management. One of these approaches is the use of AI $[1 ; 2]$.

The paper identifies the most important areas of personnel management, where the use of AI is possible. We are talking about the selection and placement of personnel, staff training, adaptation to job evaluation, etc. We consider what benefits for recruiters are the use of AI. This saves time, and better performance of many tasks and overcoming a number of mistakes made by specialists in personnel management. To justify the need for the implementation of intelligent technologies, the work provides a number of examples from the practice of wellknown companies in the world that successfully use AI.
The work reveals on which level of AI Russian companies are, what is the attitude of domestic leaders to the use of AI. Although most of the leaders of Russian companies see the many benefits in the use of AI, nevertheless, they are not ready to implement it, often referring to the risks that the implementation of AI. Therefore, in the near future, domestic leaders are faced with the problem of overcoming various barriers that impede the active use of $\mathrm{AI}$ in personnel management.

Based on well-known scientific research, the most important conclusion is made that there is a direct connection between the use of intelligent technologies and the level of development of companies. So, it was revealed that in companies where the growth rate of revenue, as shown by their forecast, will be measured in the next five years by a double-digit figure, $40.6 \%$ of managers around the world actively implement AI. In those companies where the growth rate of revenue, according to their own estimates, will be less than $10 \%$, only $18.5 \%$ of managers expressed their readiness to introduce intelligent technologies.

\section{RESEARCH METHODOLOGY}

The functioning of the personnel management system is characterized by a wide variety of problems that act as a 
contradiction to the management strategy and tactics, market conditions and company capabilities, staff qualifications, and innovation needs, etc. And each of these problems can be largely solved using AI. In the research process, such approaches as aspectual, systemic and conceptual were used. The aspect approach made it possible to choose one facet of the problem based on relevance or accounting for the resources allocated to the study. So, for example, the problem of personnel development can have an economic aspect, sociopsychological, educational, etc. A systematic approach is an approach to the research as a system in which elements of internal and external relations are identified that most significantly affect the studied results in its functioning, and the goals of each of the elements are determined based on the general purpose of the object. The conceptual approach made it possible to develop research concepts, i.e., a set of key provisions that determine the overall focus of the study. The main role in the methodology is played by research tools and methods. In the study, methods were used: formal-logical, general scientific and specific.

\section{RESEARCH PART}

Human resources management is the purposeful activity of the organization's management team, as well as managers and specialists of units of the personnel management system, which includes the development of the concept and strategy of personnel policy and personnel management methods [13].

This activity consists of the formation of a personnel management system, planning personnel work, conducting staff marketing, determining the personnel potential and the needs of the organization in personnel. The organization's personnel management technology covers a wide range of functions from hiring to firing personnel (Fig. 1)

As you know, one of the main tasks of HR specialists in companies is to hire employees of various specialties. To solve this problem, recruiters must solve a lot of problems, this is processing resumes, and processing accounts and letters of recommendation, and much more. This is a huge load. Solving these tasks, experts often make mistakes, which is the reason that people who do not fit this place can take vacant seats. The companies, in this case, spend money, often considerable, and re-hire the employee. The use of $\mathrm{AI}$ in this procedure can greatly facilitate the work of the recruiter and most of the load of the recruiter AI can take on.

With the unique analytical ability of AI, the human resources department can simultaneously receive a large amount of information about each candidate applying for a particular vacant position. Moreover, with the help of intelligent technologies, information such as evaluating the effectiveness of an employee after hiring him can be obtained in the future, and this provides important information for the recruiter to determine the potential of this employee. To cope with the solution of such problems, recruiters will need quite a lot of time, sometimes months. Personnel specialists spend $60 \%$ of their time only on reading resumes. The time that $\mathrm{AI}$ will take is an order of magnitude less. Therefore, HR specialists can actively engage AI in interviewing candidates, making a final decision on who will take the vacant seats.

Companies use various programs to effectively solve this problem. So, SAP has developed the Resume Matcher program, which helps to understand the description of vacancies, what skills are required, etc. Moreover, the program has a database that includes several tens of thousands of various anonymous resumes that were provided by the organization's clients. They indicate which of them were selected for the vacancy, which were invited for an interview, and which of them were hired. Such programs can find fresh resumes that it considers the most relevant to the criteria of the employer.

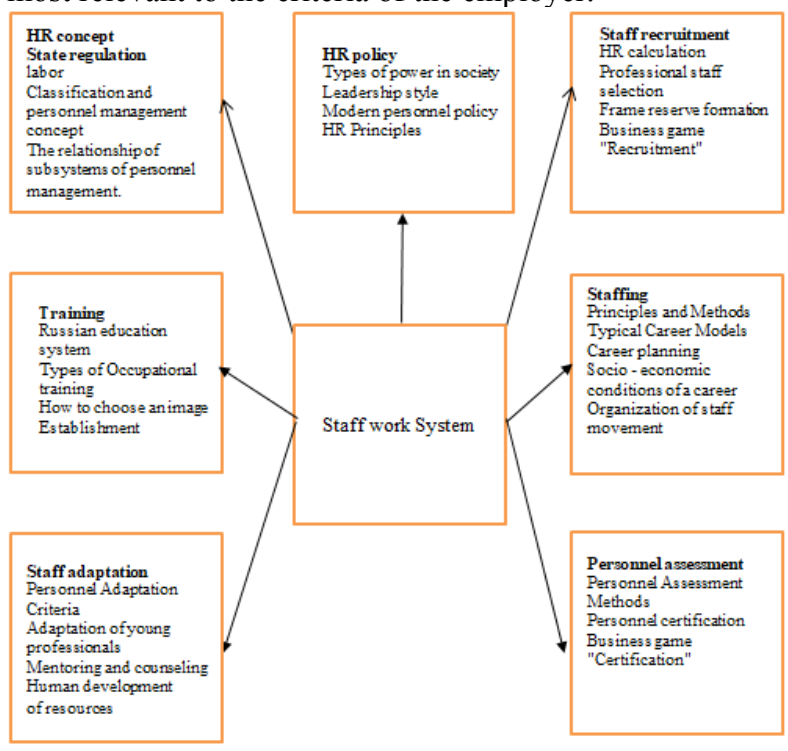

Figure 1 Human Resources System

Entelo Company has proposed its approach. The program developed by the company makes it possible for HR specialists to find candidates not based on a resume, but the information that is publicly available on the Internet. In the application available in the program, it is possible to note that these candidates are not suitable and indicate the reason, and at other times the search settings will be more accurate [4].

Veriato went even further by developing a program that makes it possible to send employee behavior messages to the company server. So, she reports on the time during which the employee spends on the sites, the time spent by the employee, not related to his activities in the company, about his attempts to access confidential information, his behavior, allowing to conclude that the employee intends to quit and leave company.

AI analyzes all this information and concludes employee productivity, and enables recruiters to correctly make decisions on personnel matters. For example, a valuable employee who is about to quit is offered a promotion or 
salary increase. Similar AI programs have the company Workday Entelo, Microsoft. and IBM.

Russian companies also try to keep up with foreign ones and actively use various programs to optimize and automate various processes in the field of personnel selection and management. So, the Russian company Stafory created the Veru robot, which is able to quickly analyze information on job portals, select a resume that is suitable for a given vacant place. The robot is also able to ring up all applicants, ask everyone questions and even conduct a video interview. In addition, Faith can analyze the answers of applicants and even determine what his emotions are. All available information goes to the employer, who then must decide whether to hire the person. Similar functions are performed by the Andrey robot. These two robots, for example, have already made 5,000 calls to select employees for Coca Cola HBC Russia [6].

$\mathrm{AI}$ is of great importance in the development and training of employees. The importance of staff training for the development of the organization has been written a lot by both foreign and domestic scientists and specialists. The urgency of the problem has been growing even more in recent years, which is associated with very rapid development and improvement of technology. Companies are changing approaches to training and development. They are forced to use a personalized approach. In these conditions, the company's management turns to the help of artificial intelligence.

"If your company does not seek to improve the skills of employees, staff will not be able to quickly adapt to new challenges and make the most of the benefits of modern technology," said Jim Link, HR Director at Randstad North America. "And if employees do not develop, then the company is doomed to stagnation" [5].

Every company, especially now, is faced with the problem of a shortage of highly qualified personnel. Of course, they can be found in the labor market, but for the company, it will be costly. Cheaper to train their staff. There are various ways of staff development. However, for this process to be fast and efficient, organizations turn to the capabilities of artificial intelligence and machine learning, which have many possibilities, creating more understandable instructions, giving much-needed feedback, a more advanced system of recommendations and conducting various training that are more personalized.

"The advantage of cognitive technology is that it can quickly and accurately process huge volumes of structured and unstructured data to find training courses that are appropriate for the experience and skills of [employees]," says James Cook, IBM's global staff development partner. "We believe that this is an excellent opportunity for human resources departments from different industries to embark on the path of digital transformation" [5].

Further training based on machine learning, of course, has a great future, however, today this system is only beginning to develop. And the main task in this direction is to determine the data that will make it possible to identify the benefits of this type of training. Some companies have already begun carrying out such experiments (for example, Dell, IBM). Soon, training with machines will be aimed at improving technical skills. In the future, it will also solve several other problems.

Great demands are placed upon applicants when applying for a job. Recently, much has been said about the use of the competency model by Russian companies. The profile is one of the main tools that is used in the selection of candidates for filling a vacant position. Also, following this document, periodic certification of personnel may be carried out or verification based on the results of the trial period. Depending on the results of the study, directions for improving qualifications can be identified. In drawing up the profile, different approaches can be used.

A typical post profile development process goes through several successive stages. In the beginning, the features of the profession are studied, as well as the requirements for it, put forward by legislative acts. It is also necessary to form a group of competent specialists who will take part in the preparation of documents.

The profile is compiled taking into account the organizational structure of the enterprise, and therefore it should also be carefully studied. The main part of the document is a description of the job responsibilities of a potential employee, as well as requirements for competencies. It is also worth paying attention to the personal qualities of applicants [7].

With the transition to the digital economy, in terms of using AI, the competency model should contain such an indicator as to the applicant's knowledge of the basic competencies of the digital economy.

Hence, very serious requirements are placed on the training of specialists. The task is to formulate and introduce into the education system the requirements for the basic competencies of the digital economy for each level of education, ensuring their continuity. The system of general, professional and additional education should work in the interests of training citizens in the digital economy and training competent specialists for it [11].

In the digital economy, the labor market the full use of competency profiles and personal development paths should be ensured.

Of course, both for companies and persons, a motivation system must be created to develop the necessary competencies and participate in the development of the digital economy.

This is an individual digital system from the state to teach children and adults the competencies of the digital economy, and advantages for entering universities, and a system of benefits for companies that train and employ citizens who have the basic competencies for the digital economy and a system of intangible benefits for employees.

To achieve all of the above tasks, normative legal acts must be adopted that provide for the regulation of flexible labor relations, including remote ones, including labor rationing, optimizing the non-productive expenditure of resources (including excessive reporting) and regulating 
the use of the personal development path of a citizen in the process of labor relations [11].

The AI capabilities are enormous in a variety of protection and compliance. Firstly, with the help of AI, in a matter of time, you can view the organization's network data and determine the area of possible errors and risks, not observing various norms, that is, the so-called "red zones" and inform HR personnel about this in the same short time so that they intervened and took appropriate action. In this case, the AI will carry out some kind of preventive work. Compared to a person, who, in order not to undermine his health, is more likely to be in the fresh air, play sports, eliminate bad habits. Secondly, if any serious violations have already occurred, $\mathrm{AI}$ is tens or even several tens of times faster than the person himself, can detect financial and other serious violations in the company in a shorter time.

So, the well-known American bank Wells Fargo, which is among the top thirty Fortune 500, fired 5.3 thousand of its employees who were convicted of fraud and he still had to pay a fine of 185 million dollars. The fact is that the bank employees, without agreeing with the customers, opened more than 2 million accounts and 500 thousand credit cards. The management of Wells Fargo Bank, creating a banking incentive system, ignored the existing potential risks that are in it. Namely: the effectiveness of the work of employees was evaluated on the number of issued cards, bonuses and an increase in the salary of employees depended directly on this indicator [15].

Another example is related to the work of the famous company Rolls Royce. So, the company decided to investigate a number of its companies, which are scattered around the world. A document selection and analysis system were used based on a solution using in-depth text analytics. The program spent only a few months on this work, revealing violations of the law in 12 countries. If ordinary employees had taken up this global task, they would have spent over a year. According to McKinsey analysts, by 2025 more than $30 \%$ of such checks in companies will be carried out using the AI system. TrustSphere, Keencorp, Volley, Cornerstone, and several other companies have achieved great success in developing such programs [3].

\section{DISCUSSION OF RESULTS}

It should be noted that over the past few years, interest in the use of artificial intelligence on the part of domestic business has increased. In 2018 alone, profits from various projects using smart technologies increased by $63 \%$. The number of managers working in banks, energy, oil and gas, telecommunications companies and who understand the need to use AI to strengthen the company's competitiveness in the market today has increased markedly. In large companies, artificial intelligence is successfully used to manage personnel, process large amounts of data, search for information, implement technologies, which simplify the analysis of documents, assess the level of risk and help make the right and highquality decisions.

Nevertheless, based on the results of a survey conducted by hh.ru experts, we can conclude that the use of intelligent technologies in personnel management in Russian companies is slow. The survey involved 800 senior managers from France, Germany, Italy, the Netherlands, Russia, Switzerland, the UK, and the USA (sample - 100 respondents per country). Large companies with a staff of more than 250 people were considered. The study was conducted from January 18 to January 27, 2019 [8].

So, only $11 \%$ of companies in Russia use AI in human resource management, $49 \%$ of those surveyed only study this problem, and $40 \%$ of employers noted that they are not interested in this topic at all. At the same time, 33\% confidently said that AI shortly will radically change the role of HR in companies (Fig. 2).

The changes will affect, according to the interviewed personnel officers, such areas of their work as, for example, interaction with candidates who did not get a job in the company, AI will be engaged in sending out refusals with an explanation of the reasons. Also, it is AI that will be able to help to determine the emotions of the candidate by his face and gestures, make an assessment of the applicant on a digital track, conduct an exit interview before leaving, replace

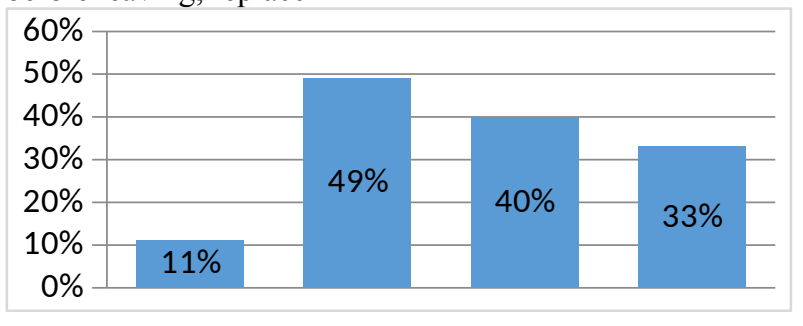

Figure 2 The attitude of managers to the use of intelligent technologies in personnel management in Russian companies trainers in digital training, and also engage in employee motivation.

Many human resources see the benefits of using AI. So, $81 \%$ of the respondents consider the benefits for HR specialists to relieve recruiters from routine actions, $75 \%$ of the respondents consider the advantage - optimization of the search for candidates, $73 \%$ consider the benefits of using AI - automation of the HR process. $72 \%$ of the respondents consider the benefits AIs include the ability to significantly reduce the time to collect and analyze a large amount of data. $61 \%$ of the advantages of using AI include the possibility of obtaining and using, in addition to a summary of other necessary information about candidates, $59 \%$ of respondents believe that AI becomes an HR partner and the main coordinator of innovation, 55\% think that using AI leads to an increase in labor productivity (Fig. 3 )

Despite the rather large advantages that AI will bear in personnel management in companies, respondents noted the risks that recruiters will face. So, $67 \%$ of the respondents expressed concern that in the process of 
In the process of applying artificial intelligence, the number of foreign business leaders is slightly less who hold the same opinion (53.0\%) (Fig. 5).

The study showed that there is a direct link between the use of intelligent technology and

the fear that decisions about candidates would be made without taking into account the human factor and emotional intelligence $(67 \%), 56 \%$ of the respondents noted that AI could pose a threat to those recruiters The benefits of using AI, according to Russian personnel officerswho are engaged in simple HR operations, so how can they lose their jobs. About half of the respondents (49\%) expressed concerns that the introduction of intelligent technologies could lead to errors in the selection process, as recruiters do not always understand what the criteria for AI

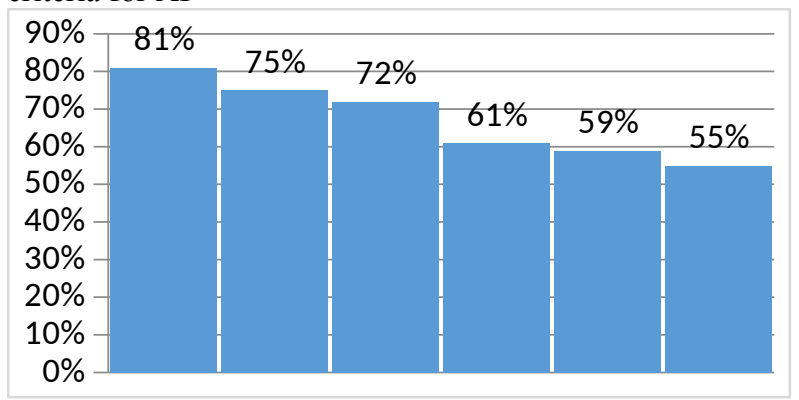

Figure 3 The benefits of using AI, according to Russian personnel officers are when choosing candidates, 35\% of respondents believe that the introduction of AI will lead to an increasing competition in the market of HR specialists (Fig. 4)

In the coming years, there is a clear trend that allows us to argue that the majority of successfully working Russian companies will actively introduce artificial intelligence into various business processes $[9,10]$.

The leaders of Russian companies not only began to introduce intelligent technologies into the business sector, but most of them $(65 \%)$ believe that they have an ethical responsibility for using artificial intelligence.

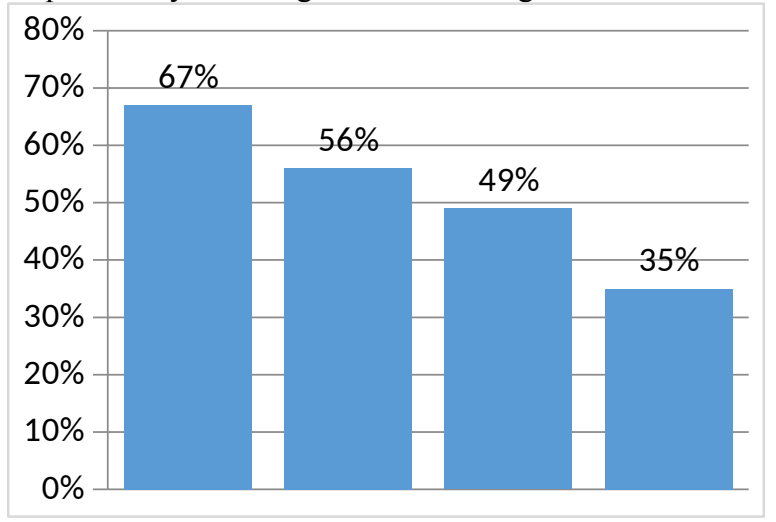

Figure 4 Risks that, according to recruiters, they will face.

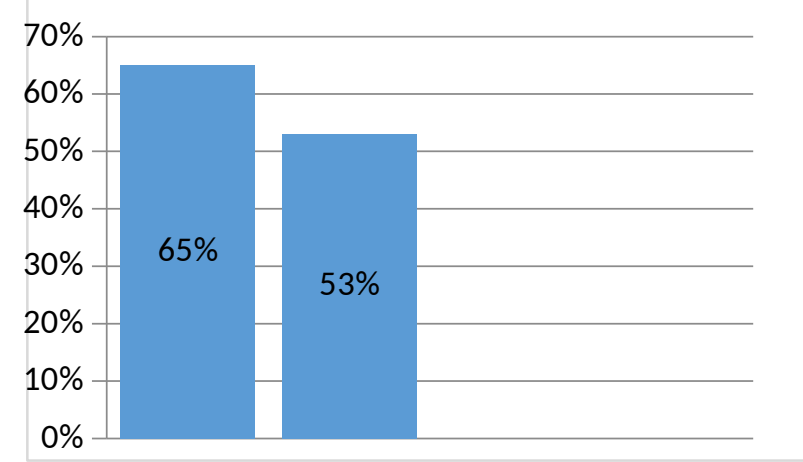

Figure 5. Share of leaders of Russian and foreign companies who believe that they should bear ethical responsibility for using AI the level of development of companies.

So, it was revealed that in companies where the growth rate of revenue, as their forecast showed, will be in the next five years measured in double

digits, $40.6 \%$ of managers around the world actively implement AI. In those companies where the growth rate of revenue, according to their estimates, will be less than $10 \%$, only $18.5 \%$ of managers expressed their willingness to introduce intelligent technologies (Fig. 6).

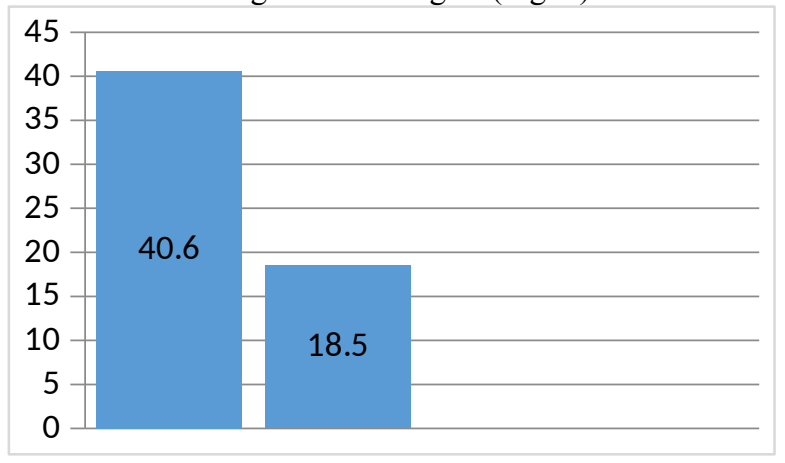

Figure 6 The share of executives in fast-growing and slow-growing companies in the world who are ready to implement AI.

The leaders of fast-growing companies, not only expressed a desire to introduce intelligent technologies in the business field but also very soon (1-3 years): $93.2 \%$ of them set the task to use AI in making decisions, we see a different picture in slow-growing companies, where $64 \%$ 


\section{REFERENCES}

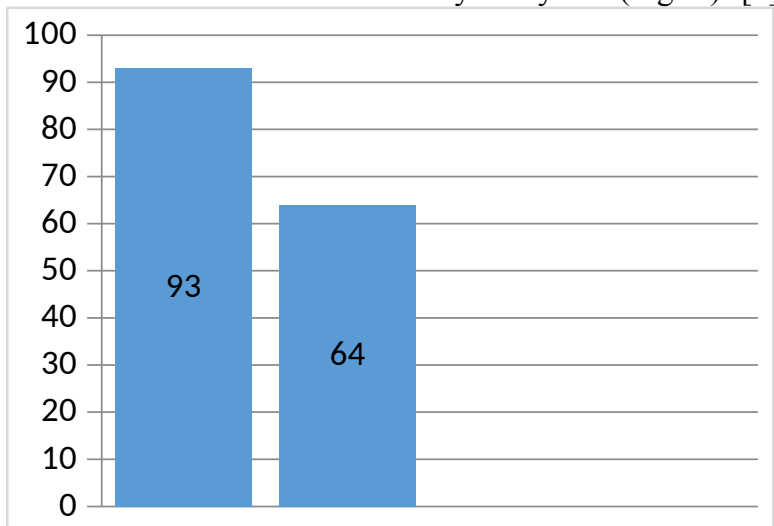

Figure 7 The share of executives of fast-growing and slow-growing companies in the world who are ready to implement $\mathrm{AI}$ in the coming years.

In the coming years, this trend can confidently defiantly be described as the active introduction of artificial intelligence in various business processes will be an innovative priority in building the concept of sustainable development of socio-economic systems $[12,14]$.

\section{CONCLUSION}

So, exploring the problem of using AI in personnel management, we can draw the following conclusions:

The need to use intelligent technologies in human resource management is being recognized by more and more companies in the world.

The use of AI in personnel management has advantages and benefits for both recruiters and the entire company. AI performs much faster and much more qualitatively tasks such as personnel selection, placement, and adaptation of personnel, personnel training, and assessment, etc.

Companies that use AI face certain risks: underconsideration of the human factor and emotional intelligence, job loss for recruiters, some mistakes in the selection process, increased competition in the HR market. The study showed that Russian companies are somewhat behind the foreign ones in the use of AI in personnel management. However, there are some successes in solving this problem. Moreover, domestic companies are faster than their Western counterparts in the pace of using AI.

An analysis of the work of many companies showed that there is a direct relationship between the effectiveness of companies and their use of intelligent technologies. So, it was revealed that in companies where managers actively implement AI, revenue growth rates in the coming years, in their opinion, will be much higher than in companies where intellectual technologies are poorly implemented.
[1] Nick Bostrom, Artificial Intelligence. Stages Threats. Strategies, Mann, Ivanov and Ferber, 2016.

[2] William Gibson, Neuromancer Trilogy "Cyberspace" St. Petersburg: ABC, 2017.

[3] Tatyana Danielyan, How artificial intelligence helps business. BUSINESS newspaper, April 12, 2017.

[4] Ted Greenwald, Artificial intelligence is changing the scope of personnel management [Electronic resource].

URL https://www.vedomosti.ru/management/articles/2017/0 3/21/682005-iskusstvennii-intellekt-personalom

[5] How artificial intelligence and machine learning help employees improve their skills [Electronic resource].

URL

https://habr.com/en/company/icl_services/blog/359234/

[6] Fashion for recruiting robots has embraced large Russian companies [Electronic resource]. URL: https: // www.vedomosti.ru/management/rekruterovhttps:/www .vedomosti.ru/management/articles/2018/02/14/750906moda-na-robotov-rekruterov

[7] Z.A. Mustafaeva, E.O. Tappaskhanova, D.D Alshagirova, Innovative approaches in the personnel management of the organization, Innovative dev. econ. 3 (45) (2018) 60-69.

[8] Russia is ahead of the United States and Europe in the active implementation of artificial intelligence [Electronic resource]. https://news.microsoft.com/en-us/ business-leaders-age-of-ai/

[9] A. Tikhonova, Artificial Intelligence in HR [Electronic resource]. https://marketmedia.ru/mediacontent/11-iskusstvennyy-intellekt/

[10]A. Kholyavko, P.Kantyshev, How artificial intelligence conquered business, Vedomosti, November 23, 2017. [Electronic resource]. URL : https://www.vedomosti.ru/ (accessed October 11, 2017).

[11]"Digital Economy of the Russian Federation" approved by the minutes of the meeting of the Presidium of the Presidential Council for Strategic Development and National Projects dated June 4, 2019 No. $7 . \quad$ [Electronic resource]. https:/digital.gov.ru/ru/activity/directions/858/ (accessed October 10, 2019). 
[12]A.A. Tatuev, A.B. Nagoev, S.A. Shanin, Innovation priorities of building the concept of sustainable development social-economic systems of region, J. Soc. Sci. 11(13) (2016).

[13]A.Y. Kibanov, V.I. Zvonnikov, Problems of training in the field of personnel management, Higher educ. in Russia, 10 (2010).

[14]A.A.Tatuev, V.V. Rokotyanskaya, O.V. Moshchenko, S.A. Shanin, Socially-oriented operating principles of innovation policy in the regional economy, Intl. Business Mgmt. 10(16) (2016) 3369-3374.

[15]Wells Fargo opened 2 million accounts without the consent of customers [Electronic resource]. https://www.kommersant.ru/doc/3084218 (accessed 11.10.2019). 